\title{
Survival rate of feldspathic ceramic veneers versus pressed ceramic veneers
}

\author{
Rata de supravieţuire a faţetelor feldspatice versus cea a faţetelor presate
}

\author{
Smaranda Buduru', Raluca Cosgarea ${ }^{1}$, Oana Baru², Maria Tiotiu³, Dorin Nenovici ${ }^{4}$ \\ ${ }^{1}$ Catedra Protetică Dentară, Facultatea de Medicină Dentară, \\ Universitatea de Medicină şi Farmacie „Iuliu Haţieganu“, Cluj-Napoca, România \\ ¿Universitatea de Medicină şi Farmacie „Iuliu Haţieganu“, Cluj-Napoca, România \\ ${ }^{3}$ Clinica Stomatologică „Stomestet", Cluj-Napoca, România \\ ${ }^{4}$ Clinica de Chirurgie OMF, Universitatea de Medicină şi Farmacie „Iuliu Haţieganu“, Cluj-Napoca, \\ România
}

\begin{abstract}
Objectives. The present study aims at evaluating the survival rates differences of feldspathic and pressed (lithium disilicate) veneers as well as the most frequent types of failure.

Material and method. 404 venners (262 feldspathic and 142 pressed) were comprised in the study and 5 types of failures were defined.

Results. $9.41 \%$ of the total veneers have suffered one form of failure. From the total number of 38 failures, 28 were feldspathic and 10 were pressed. The most frequent incidents were due to the traumatic occlusion. The survival rate was $97 \%$ at 1 year, $96.18 \%$ at 2 years and $93.54 \%$ at 5 years.

Conclusions. The statistic results revealed that the ceramic material influenced the survival rate. For a better assessment, it is recommended the study of equal groups in both materials and the same amount of time of evaluation, to exclude analysis errors.
\end{abstract}

Keywords: feldspathic veneer, pressed veneer, lithium disilicate, survival rate, failure

\section{REZUMAT}

Obiective. Articolul de faţă şi-a propus determinarea diferenţelor în rata de supravieţuire a faţetelor feldspatice şi a celor presate (litiu disilicat) şi a celor mai frecvente cauze de eşec.

Material şi metodă. S-au luat în studiu 404 faţete (262 feldspatice şi 142 presate) şi s-au definit 5 categorii de eşecuri.

Rezultate. Din totalul faţetelor luate în studiu, doar 9,41\% au suferit o formă de eşec. Din cele 38 de eşecuri, 28 au aparţinut celor feldspatice şi 10 celor presate. Cele mai frecevnte accidente au fost legate de ocluzia traumatică. Rata de supravieţuire a fost de $97 \%$ la 1 an, $96,18 \%$ la 2 ani şi $93,54 \%$ la 5 ani.

Concluzii. Rezultatele statistice au relevat că materialul din care este realizată reconstrucţia influenţează această rată de supravieţuire. Pentru o mai mare acurateţe în interpretare, pe viitor se recomandă realizarea unor eşantioane egale pentru cele două tipuri de mase ceramice studiate, iar faţetele aplicate să fie supravegheate aceeaşi perioadă de timp, evitând astfel orice tip de erori de analiză.

Cuvinte cheie: faţetă feldspatică, faţetă presată, litiu disilicat, rata de supravieţuire, eşec

\section{OBIECTIVE}

Obiectivul acestei lucrări a fost să dezvăluie dacă există vreo diferenţă în ceea ce priveşte rata de supravieţuire a faţetelor feldspatice comparativ cu cele presate. Au fost analizate strict aceste două tipuri de material cu compoziţii chimice specifice ce atrag după sine proprietăţi fizice şi mecanice diferite.
În ceea ce priveşte tehnica de realizare aceasta a fost doar manuală, toate faţetele luate în studiu fiind executate de acelaşi tehnician. Clinic, a fost respectat acelaşi protocol operator şi s-au utilizat aceleaşi materiale de către cei 3 medici curanţi.

$\mathrm{Au}$ fost urmărite şi eşecurile survenite la aceste reconstrucţii şi dacă acestea au fost corelate cu compoziţia chimică a ceramicii din care au fost realizate. 


\section{MATERIAL ŞI METODĂ}

În vederea obţinerii răspunsurilor la ipotezele formulate anterior, s-a realizat un studiu retrospectiv in vivo utilizând baza de date ale unei clinici stomatologice private din Cluj-Napoca. Din întreaga arhivă, s-au selectat dosarele cazurilor care au fost tratate prin faţete ceramice.

$\mathrm{Au}$ fost incluşi în studiu 100 de pacienţi, trataţi prin 404 faţete, dintre care 262 feldspatice (Vita VM7) şi 142 presate (Emax Press şi Emax Ceram). Criteriile de includere au fost: pacienţi clinic sănătoşi, cu igienă corespunzătoare (indici de placă sub $15 \%$ ), care au intrat în programul de control periodic. S-au exclus cazurile pacienţilor cu inflamaţie gingivală severă datorată igienei deficitare, parafuncţii necontrolate (continuarea ticurilor, nepurtarea gutierelor), cei necomplianţi, care nu s-au prezentat la controalele periodice, precum şi cei care şi-au schimbat domiciliul, fiind dificil de contactat.

Cazurile au fost ţinute sub supraveghere pe o perioadă de maximum 7 ani. Dintre informaţiile incluse în fişă, s-au urmărit consemnările medicului curant legate de: vârsta, sexul, ocupaţia pacientului, data colajului faţetelor, materialul din care au fost realizate (ceramică feldspatică sau presată), accidentele survenite şi cauzele apariţiei lor. Pentru situaţiile clinice care au prezentat insucces, am notat timpul scurs între cimentarea faţetei şi momentul apariţiei evenimentului, pentru a putea calcula cu exactitate rata de supravieţuire. Toate cazurile în care a apărut un efect neaşteptat, nedorit, care au necesitat modificări ulterioare ale reconstrucţiei, au fost definite ca eşec terapeutic. Pentru o mai bună interpretare a datelor, s-a realizat o organizare a tipului de eşec survenit, în 5 categorii distincte, şi anume:

1. accidente intraoperatorii - fisuri, fracturi, consecinţe ale aplicării unei presiuni excesive în timpul cimentării;

2. eşec datorat colajului defectuos - descimentare, infiltraţii marginale;

3. accidente datorate nerespectării de către pacient a instrucţiunilor date de medic - incizie aliment dur, traumatism dentar;

4. accidente datorate ocluziei traumatice - ciobire, fisură (nepurtarea gutierei de protecţie la pacienţii cu bruxism, ticuri necontrolate);

5. eşec estetic: culoare necorespunzătoare a ceramicii sau a răşinii de cimentare sau modificarea percepţiei pacientului asupra formei şi lungimii reconstrucţiilor la finalul tratamentului protetic.

La încheierea studiului, datele culese au fost organizate, iar mai apoi, au fost aplicate teste de statistică descriptivă, precum şi testul Kaplan-Meier, care a oferit răspunsul în ceea ce priveşte supravieţuirea faţetelor.

\section{REZULTATE}

La sfârşitul perioadei de observaţie, informaţiile adunate au fost analizate şi supuse unor teste statistice. Diversitatea datelor a facilitat o mai bună stratificare a rezultatelor.

Cazurile incluse în studiu au fost ţinute sub supraveghere un interval diferit de timp, perioada medie fiind de 25,9 luni (aproximativ 2 ani), cu un minim de 4,7 luni. Însă au existat şi cazuri care au fost tratate în urmă cu 93,43 luni (7 ani) care au permis extragerea unor informaţii valoroase în ceea ce priveşte statusul faţetelor în timp.

Un aspect important al studiului a fost depistarea tipului de accidente care se petrec cel mai des şi care este frecvenţa lor. Din totalul de 404 faţete, doar 38 au înregistrat un anumit tip de eveniment, din cele 5 categorii menţionate anterior $(9,41 \%)$ (Fig. 1).



FIGURA 1. Rata eşecului fațetelor ceramice

La o analiză mai atentă, pe categorii de materiale, s-a observat că 28 dintre cele 38 de eşecuri au apărut la faţetele feldspatice şi restul de 10, la cele din litiu disilicat. Astfel 10,68\% din faţetele feldspatice, respectiv $7 \%$ din cele presate au înregistrat un eveniment.

Statistica realizată a permis stratificarea informaţiei, astfel încât să se poată determina care sunt cele mai frecvente tipuri de eşec din cele 5 categorii (Fig. 2). 


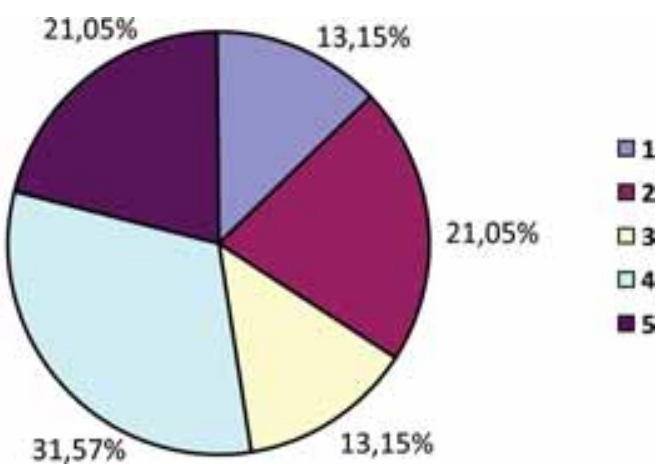

FIGURA 2. Frecvența eşecurilor pe categorii: 1. accidente intraoperatorii; 2. eşec datorat colajului defectuos; 3. accidente datorate nerespectării de către pacient a instrucțiunilor date de medic; 4. accidente datorate ocluziei traumatice; 5. eşec în alegerea culorii.

Odată cu obţinerea acestor informaţii legate de cele mai frecvente tipuri de probleme care au intervenit pe parcursul studiului, s-au utilizat datele culese iniţial pentru a descoperi care este rata de supravieţuire a faţetelor cimentate.

Pentru interpretare s-a folosit testul statistic Kaplan-Meier. Acest test a necesitat definirea unor parametri şi anume, supravieţuirea, care a fost calculată prin diferenţa de timp între momentul aplicării faţetei până la sfârşitul studiului, respectiv momentul apariţiei eşecului. Ulterior, s-a stabilit cenzura notată cu 0 în cazul în care eşecul nu s-a petrecut sau cu 1 pentru situaţiile care au prezentat acest eveniment. În vederea calculării exacte a ratei de supravieţuire s-a stabilit că faţetele care s-au descimentat, fisurat, ciobit şi fracturat, nu au supravieţuit. Rezultatele obţinute sunt reprezentate în Fig. 3, putând fi interpretate la intervale diferite de timp. Astfel la un an, supravieţuirea a fost de $\mathbf{9 7 \%}$, iar la 2 ani de $\mathbf{9 6 , 1 8 \%}$ (Fig. 4). După cum se observă ea nu diferă foarte mult, între cele două perioa-


această valoare menţinându-se constantă, indiferent de trecerea timpului (Fig. 5).

Ulterior, s-a aplicat acelaşi test statistic (KaplanMeier) pentru a determina dacă supravieţuirea faţetelor depinde de materialul din care au fost realizate (ceramică feldspatică sau ceramică presată). În Tabelul 1 se regăsesc informaţiile centralizate şi calculate de test. După cum se observă, grupul faţetelor realizate din ceramică presată litiu disilicat a înregistrat doar un eveniment care a determinat încheierea perioadei de supravieţuire, în timp ce faţetele feldspatice au prezentat 17 astfel de evenimente. Prin urmare şi valorile mediei perioadei de supravieţuire a celor două tipuri de reconstrucţii au fost diferite în favoarea grupului de faţete presate (92,75\% presate "EM"; 86,94\% feldspatice "FF") (Tabelul 2).

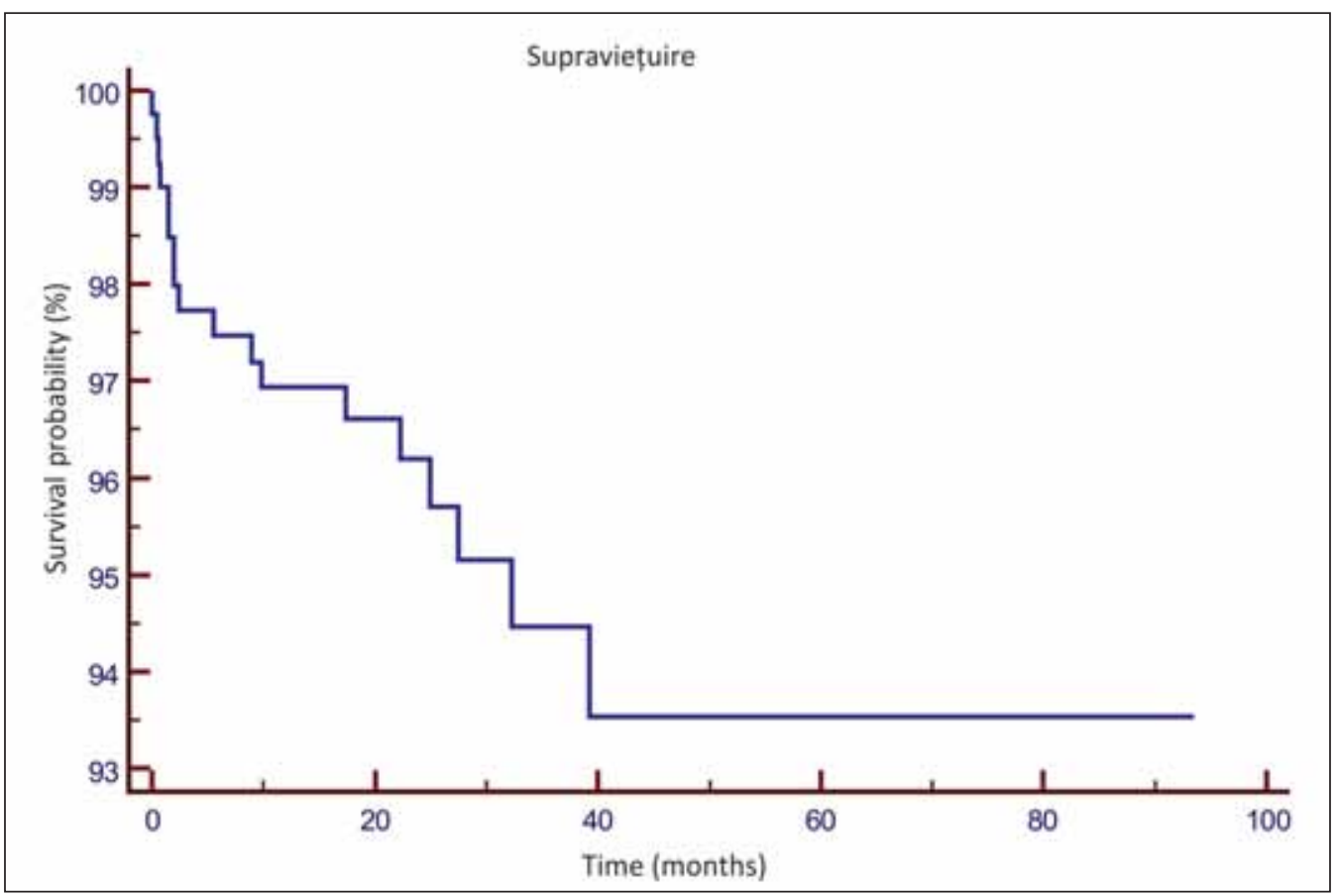

FIGURA 3. Rata de supraviețuire a fațetelor 

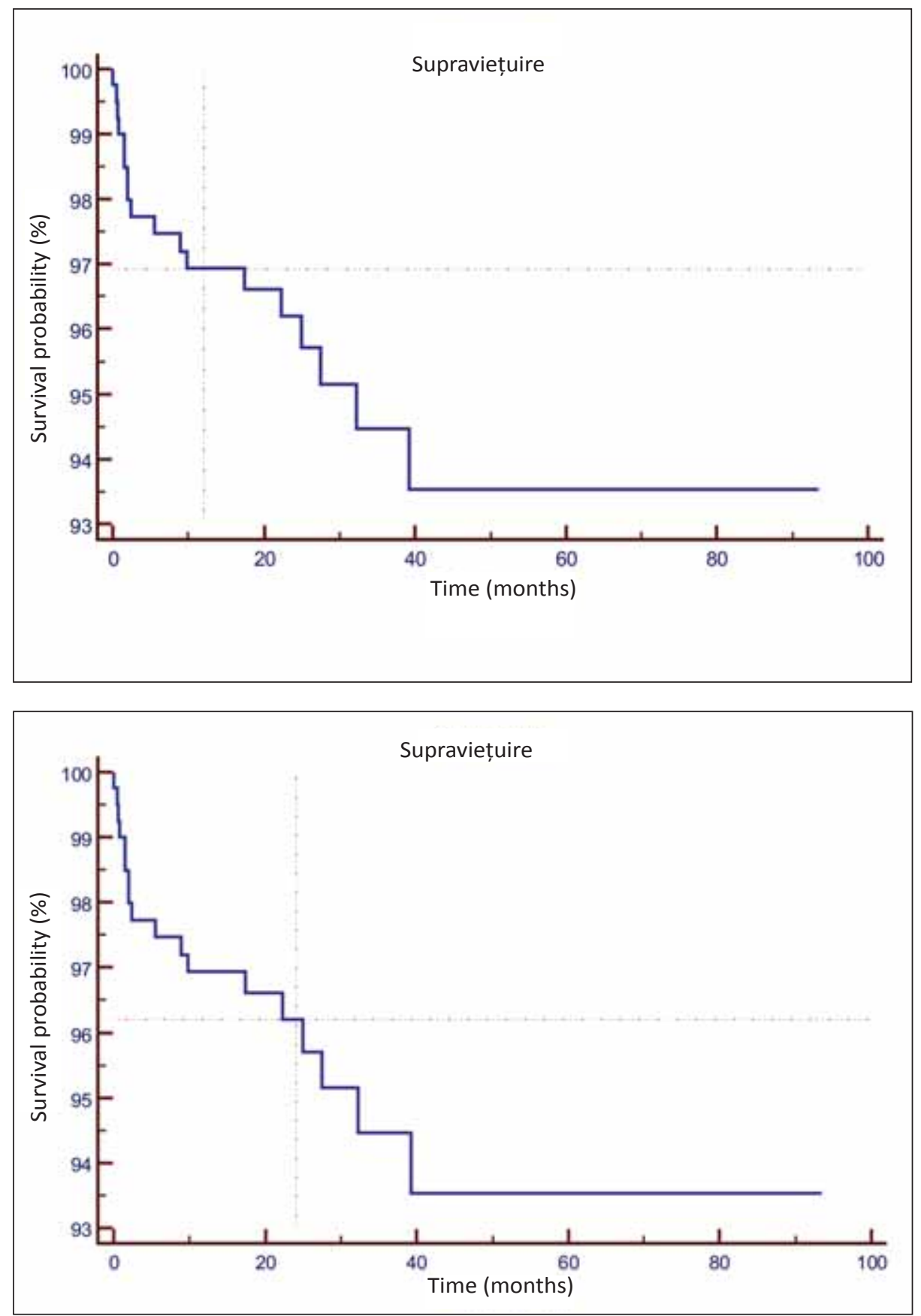

FIGURA 4. Rata de supraviețuire a fațetelor la 1 an (sus), rata de supraviețuire a fațetelor la 2 ani (jos)

TABELUL 1. Rezumatul evenimentelor înregistrate

\begin{tabular}{|l|c|c|c|c|}
\hline & \multicolumn{2}{|c|}{ Number of events } & \multicolumn{2}{c|}{ Number censored } \\
\hline Factor & $\mathrm{N}$ & $\%$ & $\mathrm{~N}$ & $\%$ \\
\hline EM & 1 & 0.70 & 141 & 99.30 \\
\hline FF & 17 & 6.51 & 245 & 93.49 \\
\hline Overall & 18 & 4.47 & 385 & 95.53 \\
\hline
\end{tabular}

TABELUL 2. Media perioadei de supraviețuire pentru cele două tipuri de fațete

\begin{tabular}{|l|c|c|c|}
\hline Factor & Mean & SE & 95\% Cl for the mean \\
\hline EM & 92.757 & 0.674 & 91.437 to 94.077 \\
\hline FF & 86.949 & 1.529 & 83.951 to 89.947 \\
\hline Overall & 88.475 & 0.829 & 86.850 to 90.100 \\
\hline
\end{tabular}

În Fig. 6 se regăsesc curbele de supravieţuire pentru cele două categorii de restaurări estetice, putându-se observa diferenţa dintre ele.

S-a aplicat testul Hi pătrat pentru a determina dacă există vreo diferenţă între rata de supravieţuire a celor două materiale (Tabelul 3). Valoarea lui p a fost de 0,0236, inferioară valorii de 0,05 , ce atrage după sine validarea ipotezei conform căreia există o diferenţă între supravieţuirea în timp a faţetelor feldspatice şi cele presate. Prin urmare, faţetele litiu disilicat au o supravieţuire mai mare în timp. 


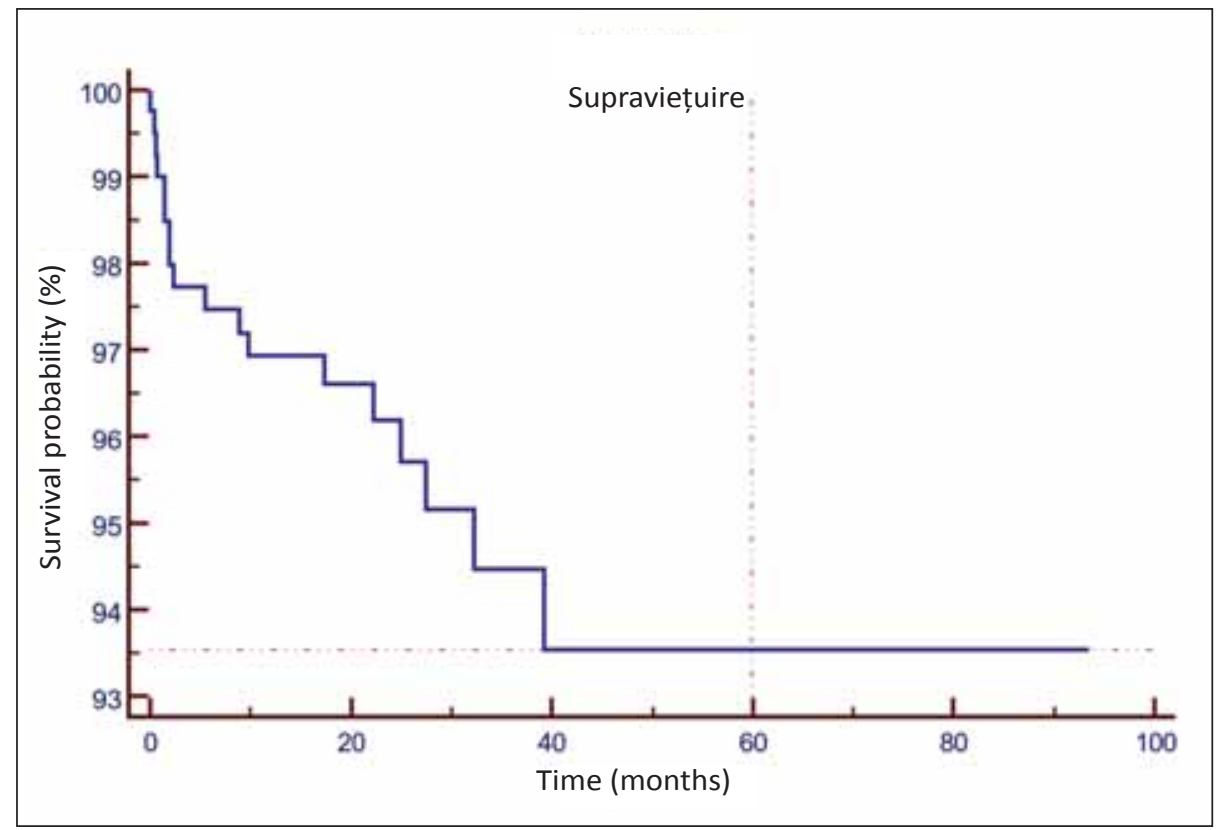

FIGURA 5. Rata de supraviețuire a fațetelor la 5 ani

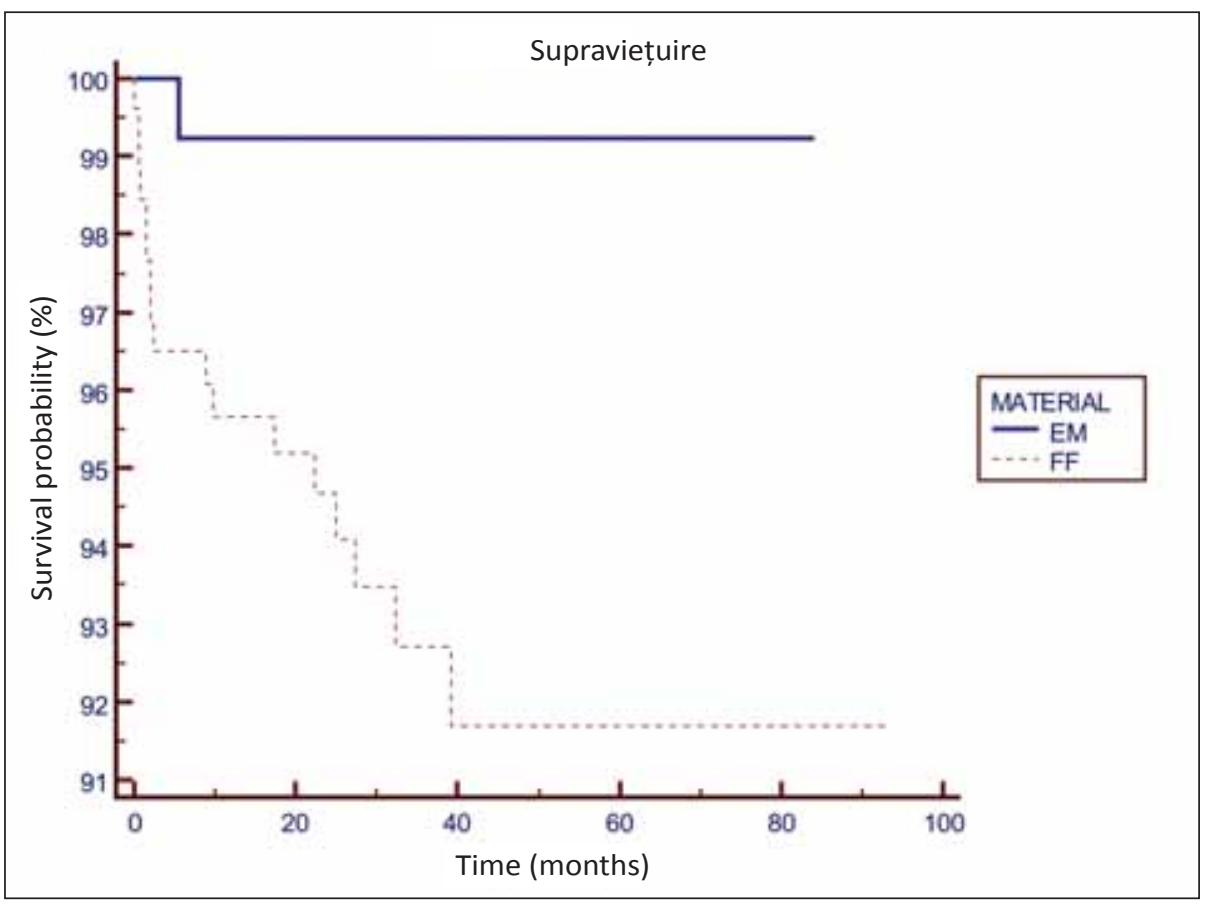

FIGURA 6. Rata de supraviețuire a fațetelor feldspatice şi presate

TABELUL 3. Testul Chi pătrat

\begin{tabular}{|l|l|}
\hline Chi-squared & 5.1251 \\
\hline DF & 1 \\
\hline Significance & $\mathrm{P}=0.0236$ \\
\hline
\end{tabular}

\section{DISCUŢII}

La ora actuală există multiple studii care au testat supravieţuirea faţetelor in-vivo şi in-vitro. Cele realizate in-vivo oferă informaţii mult mai complexe şi mai veridice deoarece condiţiile existente în cavitatea orală nu pot fi reproduse în totalitate in vitro. In-vivo există foarte multe variabile care ţin de pacient, medici, tehnicieni, materiale, evenimente neprevăzute. Un plus al acestui studiu a fost realizarea reconstrucţiilor de către acelaşi operator (tehnician), iar impunerea unui protocol clinic strict (referitor la materiale şi etape clinice) a redus o parte din variabile.

În prezentul studiu, faţetele feldspatice şi presate aplicate au fost asociate cu o rată mare de supra- 
vieţuire: $93,54 \%$ la 5 ani, rezultat comparabil cu cele din literatura de specialitate: $94.4 \%$ la 12 ani - Mauro Fradeani (2005) (1), 91\% la 10 ani - Dumfahrt H, (2), 97.5\% la 7 ani - D'Arcangelo C (2012) (3), $85 \%$ la 5 ani - Guess PC (2008) (4), 94,6\% la 3 ani - Gresnigt M (2013) (5).

Supravieţuirea înregistrată de reconstrucţiile din ceramică litiu disilicat $(92.757 \%)$ în cadrul acestui studiu a fost superioară celor din ceramică feldspatică $(86.949 \%)$. O explicaţie în acest sens ar fi şi numărul mai redus de reconstrucţii presate realizate, precum şi dimensiunea redusă a cazuisticii globale.

La analiza frecvenţei fiecărui tip de eşec în funcţie de materialul din care au fost realizate, se observă că faţetele feldspatice au suferit mai multe accidente datorate traumei ocluzale, precum şi accidente intraoperatorii, decât reconstrucţiile litiu disilicat aflate sub observaţie. Acest rezultat susţine informaţiile existente, conform cărora ceramica feldspatică are o rezistenţă mecanică inferioară celei presate (6-9). Eşecul predominat în grupul faţetelor litiu disilicat a fost reprezentat de culoare $(10,11)$.

\section{CONCLUZII}

Cercetarea cuprinsă în lucrarea de faţă a evidenţiat rezultate pozitive şi cele mai frecvente eşecuri.

\section{BIBLIOGRAFIE}

1. Fradeani M., Redemagni M., Corrado M. Porcelain laminate veneers: 6 to 12 year clinical evaluation - a retrospective study. Int J Periodontics Restorative Dent. 2005; 25(1):9-17.

2. Dumfahrt H. Porcelain laminate veneers. A retrospective evaluation after 1 to 10 years of service: Part I-Clinical procedure. Int J Prosthodont. 1999; 12(6):505-13.

3. D'Arcangelo C., De Angelis F., Vadini M., D'Amario M. Clinical evaluation on porcelain laminate veneers bonded with light-cured composite: Results up to 7 years. Clin Oral Investig. 2012; 16(4):1071-9.

4. Guess P.C., Stappert C.F. Midterm results of a 5-year prospective clinical investigation of extended ceramic veneers. Dent Mater. 2008; 24(6):804-13.

5. Gresnigt M.M., Kalk W., Özcan M. Clinical longevity of ceramic laminate veneers bonded to teeth with and without existing composite restorations up to 40 months. Clin Oral Investig. 2013; 17(3):823-32.

6. Decurcio R.A., Cardoso P.C. Laminados cerâmicos: um procedimento estético minimamente invasivo. Stomatos. $2011 ; 17(33): 12-9$.
S-a observat că ceramica feldspatică oferă posibilitatea obţinerii unor plaje de culoare superioare celei presate, neajunsurile acestui material remarcându-se la capitolul rezistenţă. În schimb ceramica presată oferă o siguranţă mai mare în ceea ce priveşte proprietăţile mecanice, având o rezistenţă triplă la flexie faţă de cea feldspatică (306-400 MPa ceramica litiu disilicat, $90 \mathrm{MPa}$ ceramica feldspatică).

Un alt aspect deosebit de important este reprezentat de rata de supravieţuire a faţetelor, deoarece atât medicii cât şi pacienţii doresc ca rezultatele sa fie şi durabile, nu doar estetice. Studiile de referinţă, cât şi studiul de faţă au evidenţiat o supravieţuire favorabilă odată cu trecerea timpului de $93,54 \%$. De asemenea, rezultatele statistice au relevat că materialul din care este realizată reconstrucţia influenţează această rată de supravieţuire. Pentru o mai mare acurateţe în interpretare, pe viitor se recomandă realizarea unor eşantioane egale pentru cele două tipuri de mase ceramice studiate, iar faţetele aplicate să fie supravegheate aceeaşi perioadă de timp, evitând astfel orice tip de erori de analiză.

Conflict of interest: none declared Financial support: none declared

7. Da Cunha L.F., Reis R., Santana L., Romanini J.C., Carvalho R.M., Furuse A.Y. Ceramic veneers with minimum preparation. Eur J Dent. 2013; 7(4):492-6.

8. Gurel G., Sesma N., Calamita M.A., Coachman C., Morimoto S. Influence of enamel preservation on failure rates of porcelain laminate veneers. Int J Periodontics Restorative Dent. 2013; 33(1):31-9.

9. Vailati F., Gruetter L., Belser U.C. Adhesively restored anterior maxillary dentitions affected by severe erosion: up to 6 -year results of a prospective clinical study. Eur J Esthet Dent. 2013; 8(4):506-30.

10. Barizon K.T., Bergeron C., Vargas M.A., Qian F., Cobb D.S., Gratton D.G. et al. Ceramic materials for porcelain veneers: Part II. Effect of material, shade, and thickness on translucency. J Prosthet Dent. 2014.

11. Giordano R., McLaren E.A. Ceramics overview: Classification by microstructure and processing methods. Compend Contin Educ Dent. 2010; 31(9):682-4. 